\title{
A imagem física do mundo: de Parmênides a Einstein
}

\section{JOSÉ LEITE LOPES}

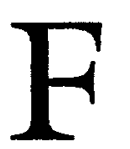

alar de Einstein, escrever sobre Einstein é certamente um desafio fascinante porém perigoso: quantos artigos, quantos livros não lhe foram dedicados, a ele e a sua obra, desde os anos 50 , últimos anos de vida? Quantos discursos náo foram feitos, quantos congressos não foram realizados há exatamente quatro anos, por ocasiáo do centenário de seu nascimento?

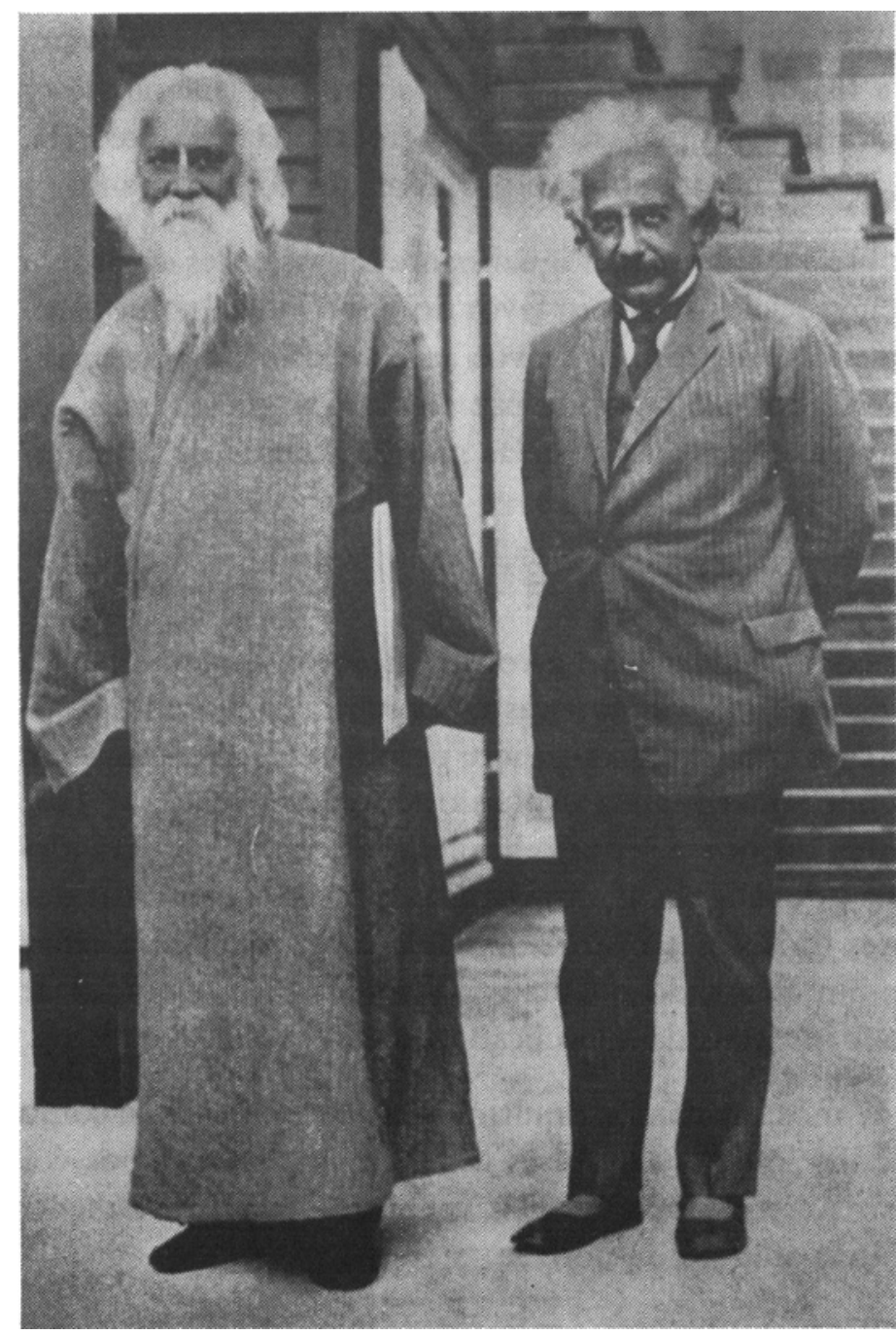

O poeta e mistico indiano Rabindranath Tagore (1861-1941), Prêmio Nobel de Literatura em 1913, foi recebidio na Alemanba pelo fisico alema Albert Einstein (1879-1955), Premio Nobel de Fisica 1921 
Se, do mesmo modo que Galileu e Newton, ele é considerado pelos físicos como uma das maiores figuras da história dessa ciência, é porque suas contribuiçóes científicas formam a base da física contemporânea: seus trabalhos sobre a teoria da relatividade restrita provocaram uma reformulaçáo revolucionária da física tradicional, das noçóes fundamentais de espaço e tempo, de matéria e energia; seus trabalhos sobre a teoria da gravitação - talvez os mais belos da física teórica até os dias de hoje - ocasionaram a unificação da dinâmica gravitacional com a geometria do espaço físico. E seus escritos sobre a natureza da luz, sobre a teoria quântica dos processos de emissão e de absorção dos fótons pelos átomos, contribuíram para a eclosão da mecânica quântica teoria que atualmente é a teoria universal dos objetos e dos fenômenos microscópicos, escala dos átomos, dos núcleos e das partículas fundamentais da matéria.

E sobretudo, ao longo de sua vida, à medida que se desenvolviam suas idéias sobre a física, era levado a refletir sobre os princípios e as motivaçóes da pesquisa científica, sobre os métodos da física teórica, sobre sua concepção do mundo, sobre o problema do conhecimento.

Náo falarei sobre suas atividades igualmente importantes de ordem política, econômica e social, não só em favor do povo judeu, como também em prol da justiça para com os povos árabe e palestino; mencionarei apenas seus esforços em favor da paz e contra a guerra, suas reflexōes e suas inúmeras intervençōes pelas grandes causas da humanidade.

\section{O problema do conhecimento}

Se desejamos compreender bem a contribuiçáo de Einstein para a descrição - e compreensáo - de um vasto conjunto de fenômenos físicos, talvez devêssemos nos fazer a seguinte pergunta: qual é a imagem física atual do mundo, qual foi sua evolução através da história? Essa pergunta é tão antiga quanto o próprio homem; é o cerne dos grandes sistemas de filosofia e de religiáo. E, em virtude de minha ignorância dos estudos dos maiores filósofos e historiadores da ciência, só seria capaz de apresentar-lhes um apanhado qualitativo e sumário da evoluçáo de alguns aspectos fundamentais da concepçáo física do mundo.

O problema de mostrar como adquirimos o conhecimento e como se realiza nosso conhecimento das coisas distintas de nós mesmos é o núcleo da filosofia. Acredito que ele náo encontrou e provavelmente jamais encontrará uma solução definitiva.

Para George Berkeley, filósofo inglês do século XVIII, os corpos 
materiais existem apenas em nossa percepção; negando a existência da matéria, ele revelou, de certo modo, $o$ aspecto crucial desse problema. Ao postulado da existência independente das coisas que correspondem às nossas sensaçóes, preferiu admitir a existência de Deus que está olhando sempre as coisas; dessa forma, ainda que um objeto deixe de existir para mim quando não o percebo, ainda que ele recomece a existir assim que o percebo novamente, a vigilância contínua de Deus que perceberia eternamente os objetos eliminaria essa intermitência da existência dos corpos, reestabeleceria sua continuidade (ver Quadros I e II).

\section{Quadro I}

4. "It is indeed an opinion strangely prevailing amongst men, that houses, mountains, rivers, and in a word all sensible objects have an existence natural or real, distinct from their being perceived by understanding. But with how great an assurance and acquiescence soever this principle may be entertained in the world; yet whoever shall find in his heart to call'it in question may, if I mistake not, perceive it to involve a manifest contradiction. For what are the forementioned objects but the things we perceive by sense, and is it not plainly repugnant that any one of these or any combination of them should exist unperceived?"

George BERKELEY, A Treatise Concerning the Principles of Human Knowledge, PART I.

\section{Quadro II}

33. "The ideas imprinted on the senses by the Author of Nature are called real things, and those excited in the imagination being less regular, vivid and constant, are more properly termed ideas, or images of things, which they copy and represent."

"72. ... To me, I say, it is evident that the being of a spirit infinitely wise, good and powerful, is abundantly sufficient to explain all the appearances of Nature. But as for inert senseless matter, nothing that I perceive has any the least connexion with it, or leads to the thoughts of it.

George BERKELEY, Loc. Cit., PART I 
À imensa variedade de nossas sensaçóes e percepções, associamos um mundo que existe fora de nós, e que é a causa de nossas percepçóes, uma existencia que náo $\delta$, todavia, segundo a física contempordnea, totalmente independente de nós. A essas percepçóes associamos, então, coisas e fenômenos - que são construçốes para exprimir nossas percepçốes, inclusive aquelas transmitidas por um aparelho de medida física -; nestas construçóes e, em correspondência com os objetos, empregamos idéias inventadas pelo pensamento, noçóes primitivas e noções logicamente deduzidas, construçóes que se integram em uma teoria. $\mathrm{E}$ o conjunto das teorias, que se propóem a descrever as regularidades de certas classes de objetos e de fenômenos, contribuirá para a formaçáo de uma imagem física do mundo.

Segundo Eugene Wigner, grande físico teórico contemporâneo, existem duas espécies de realidades ou de existências: a existência de minha consciência e a existência de todo o resto, ou seja, o mundo material e as sensaçóes dos outros. A existência de um objeto, de um livro, por exemplo, é uma expressão apropriada para descrever as sensaçóes que experimento e que determinam outras sensaçóes. Trata-se, portanto, de uma realidade relativa, ao passo que, para Wigner, a realidade absoluta é a realidade de minha consciência. Essa concepção resulta, com efeito, da análise da noção de medida em mecânica quântica. Em uma medida física, há interação entre o aparelho e o objeto observado, e o estado do sistema aparelho + objeto permanece tal que apenas um estado do objeto pode estar associado com um dado estado do aparelho. Assim, a medida do estado do aparelho conduz à medida do objeto físico e essa apenas é concluída quando sua indicação entra em minha consciência.

"This last step", afirma Wigner, "is, at the present state of our knowledge, shrouded in mystery and no explanation has been given for it so far in terms of quantum mechanics, or in terms of any other theory." (Quadro III)

Assim, antes de George Berkeley, entre George Berkeley e Eugene Wigner, quantas extraodinárias reflexóes e análises sobre a natureza de nosso conhecimento, sobre a estrutura daquilo que chamamos mundo físico!

Os físicos estão interessados nas regularidades que se revelam na observaçáo das coisas e dos fenômenos. Suas teorias só conseguem descrever a enorme complexidade do mundo físico porque existem certas correlaçóes entre fenômenos, regularidades, certas proporçōes que convencionamos chamar leis naturais. $O$ trabalho e o esforço dos físicos 
consistem em descobrir essas leis e as condiçóes iniciais que permitem encontrar as soluçóes e, através das próprias leis, estabelecer prediçóes.

A pesquisa do conhecimento através da contemplação da variedade das coisas conduziu, já na Grécia clássica, à noção de necessidade, de proporçáo entre os elementos, à idéia da existência de elementos constitutivos da matéria.

\section{Quadro III}

"Even though it is not strictly relevant, it may be useful to give the reason for the increased interest of the contemporary phisicists in problems of epistemology and ontology. The reason is, in a natushell, that physicists have found it impossible to give a satisfactory description of atomic phenomena without reference to the consciousness. This had little to do with the oft rehashed problem of wave and particle duality and refers, rather, to the process called 'reduction of the wave packet'. This takes place whenever the result of an observation enters the consciousness of the observer - or, to be even more painfully precise, my own consciousness, since I am the only observer, all other people being only subjects of my observation. Alternatively, one could say that quantum mechanics provides only probability connections between the results of my observations as I perceive them. Whichever formulation one adopts, the consciousness evidently plays an indispensable rôle."

Eugene P. WIGNER, Two Kinds of Reality, The Monist, Vol. 48. no 2, 1964.

\section{A Escola de Mileto}

Tales foi um dos primeiros a enunciar a idéia da existência de um elemento fundamental, de uma substancia primordial. Segundo ele, todas as coisas seriam feitas de água. Como a água contém átomos de hidrogênio, essa concepção não está em contradição com as idéias modernas de astrofísica: da observaçáo de material cósmico, deduz-se que os elementos predominantes no estágio inicial do Universo eram o hidrogênio e o hélio, em uma proporção de abundância de hidrogênio dez vezes superior à do hélio. Já Anaximandro, outro filósofo da escola de Mileto, afirmava que a substância primordial de todas as coisas não $\mathfrak{c}$ a ägua, nem, efetivamente, nenhum outro corpo material conhecido. Para ele, o elemento fundamental de todas as coisas é infinito e eterno e está subjacente em todos os mundos. Essa substância se transforma em 


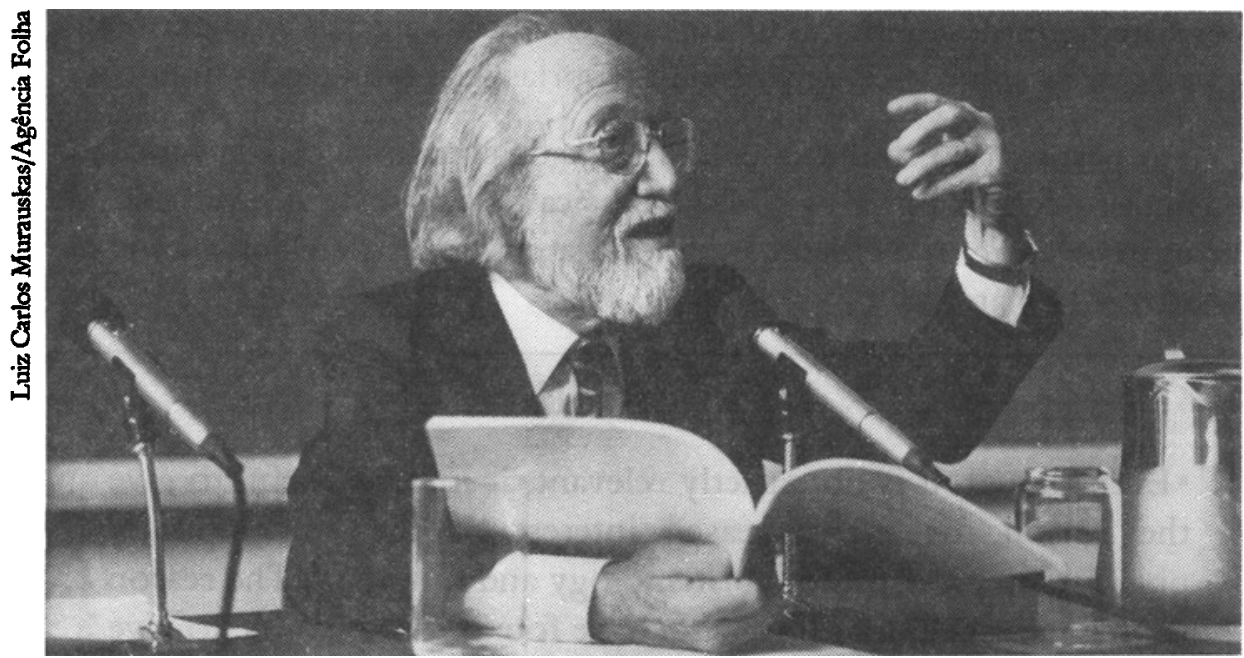

Leite Lopes fez a Conferência do Mès de outubro de 1990 do IEA sobre "Fisica e Cultura"

objetos materiais que nós percebemos. Segundo Anaximandro, no mundo material existe uma proporção definida de ar, de fogo, de água e de terra. A competição entre esses elementos concebidos como deuses, ou seja, a proporção de tais elementos, é regulamentada por uma fatalidade, por uma certa necessidade - necessidade de proporçáo entre esses elementos - que constituiria, segundo certos filósofos, a origem da noção da lei da natureza. Para Anaxímenes, terceiro pensador da Escola de Mileto, a substância primordial é o ar. A alma do homem é feita de ar, o fogo é o ar rarefeito; ao condensar, o ar se transforma em água que, por sua vez, se condensa em terra, em pedras.

Segundo essas especulaçóes, por assim dizer, pioneiras da química, as forças de coesão seriam uma espécie de respiração: visto que nossa alma, feita de ar, nos mantém unidos e estáveis, também o ar e a respiraçáo universal asseguram a coesão, a estabilidade do mundo - o ar seria substituído no século XIX pelo éter, que trānsmitiria as açóes físicas.

As especulações dos filósofos de Mileto são, aliás, vistas por Bertrand Russel como verdadeiras hipóteses científicas, visto que nelas não encontramos nenhuma idéia de moral nem concepçóes antropomórficas.

Ao lado desse espírito científico pioneiro, os filósofos gregos estavam impregnados de certo espírito de religiosidade: os que estavam influenciados pela religiáo de Baco ou Dioniso, os discípulos de Orfeu, buscavam o entusiasmo, que significa união com o deus; interessavam-se pela aquisição de conhecimentos místicos, não-acessíveis pela percepçáo dos sentidos. A partir dos cultos de Dioniso e Orfeu, o componente místico da filosofia grega foi importante especialmente em Pitágoras e, em seguida, ganhou, através de Platão, a filosofia da Idade Média. 


\section{Pitágoras}

Atribui-se a Pitágoras a origem da palavra teoria: palavra que queria dizer estado de contemplação com afinidade e paixão. Segundo o grande scholar inglês F. M. Cornford, nesse estado o espectador se identifica com o Deus que sofre, " morre em sua morte e renasce em seu novo nascimento". Segundo Pitágoras, a contemplaçáo com afinidade e paixão é uma atividade intelectual que dá origem ao conhecimento matemático. Devemos a ele a afirmação de que todas as coisas são números, afirmação essa que, depois de Galileu e Newton, incorporou-se à física e pode ser encontrada nos trabalhos de Maxwell e Lorentz, de Einstein, de Schrödinger e Dirac, assim como no trabalho dos físicos contemporâneos sobre as teorias dos campos de calibre - talvez as coisas provenham de um grande grupo de calibre, de suas representaçóes, de sua espontânea quebra de simetria.

Eis um resumo de um apanhado geral da filosofia dos Pitagóricos feito por Alexander Polyhistor no século I a.C. e reproduzido por Diógenes de Laerta: "O primeiro princípio de todas as coisas é o Um. Do Um proveio um Dois indefinido, enquanto Matéria para o Um que é causa. Do Um e do indefinido Dois provieram os números; dos números, os pontos; dos pontos, as linhas; das linhas, as figuras planas; das figuras planas, as figuras sólidas; das figuras sólidas, os corpos sensíveis. Os elementos deste último sáo quatro: fogo, água, terra, ar; esses elementos mudam e se transformam e deles resulta um Cosmo, animado, inteligente, esférico, que compreende a terra que é, ela própria, esférica e habitada por todos os lados" (citação de Cornford).

O que dizemos hoje? Talvez isto: os primeiros elementos de todas as coisas são léptons e quarks; dos quarks provêm os hádrons, entre os quais os bárions; os bárions geram os núcleos; os léptons e os núcleos formam os átomos dos corpos sensíveis. Desses léptons, quarks, núcleos e átomos resulta um Cosmo que compreende a matéria inanimada e a matéria inteligente que, a partir da terra, contempla o Universo e se contempla a si mesma (Quadro IV).

\section{Heráclito e Parmênides}

Belas divagaçóes filosóficas também nos foram legadas por Heráclito (século $\mathrm{V}$ a.C.). Ele considerava o fogo como substância primordial, visto que ele tem as propriedades da menos corporal e mais sutil matéria. Tal a chama do fogo, tudo nasce da morte de algo; diríamos hoje: fótons sáo emitidos (nascem) na aniquilação (morte) elétron-pósitron; pares partícula-antipartícula nascem da morte de um fóton. As- 
sim, afirmava Heráclito, os seres mortais são imortais, os imortais são mortais, um vive a morte do outro e morre a vida de um outro.

\section{Quadro IV}

No tempo dos filósofos, e mesmo antes deles, aqueles que chamamos de pitagóricos, foram os primeiros a se dedicar à matemática e fizeram-na progredir. Educados nessa disciplina, consideraram que os princípios da matemática são os princípios de todos os seres. E como desses princípios os números são, por natureza, os primeiros e que, nos números; os Pitagóricos acreditavam perceber uma multidáo de analogias com tudo aquilo que é e se torna, muito mais do que percebiam no Fogo, na Terra e na Água (certa denominação dos números era a justiça, uma outra era a alma e a inteligência, outra ainda era o tempo crítico e, assim por diante, por assim dizer, para cada uma das outras determinaçóes). Como viam, além disso, que números exprimiam as propriedades e as proporçóes musicais, como, enfim, todas as outras coisas lhes pareciam, em sua natureza inteira, ser formadas à semelhança dos números, e que os números pareciam ter as realidades primordiais do Universo, nessas condiçóes, consideraram que os princípios dos números sã́o os elementos de todos os seres, e que o Céu, na sua totalidade, é harmonia e número.

ARISTÓTELES, La Métaphysique, A, 5, 985 b, 25.

No mundo existe unidade, mas essa unidade é o resultado da combinação de opostos: o Um é feito de todas as coisas e todas as coisas resultam do Um. A oposição dos contrários é fundamental, uma harmonização de tensóes opostas, como o arco e a lira; talvez possamos, entáo, dizer que tanto a noção de conjugação de carga como a de aniquilação matéria-antimatéria, para produzir energia, remontam a $\mathrm{He}$ ráclito.

Com Parmênides de Eléa, um pitagórico dissidente, foi introduzida a noção do Um, de um ser substancial eterno e imutável. Ele rejeitou o postulado de Pitágoras segundo o qual do Um original provêm dois e, em seguida, vários. Eis algumas de suas premissas:

1) $O$ que $\ell, b$, e não pode não ser; o que não $\dot{E}$, não $\delta$, e não pode ser.

2) $O$ que $b$, pode ser pensado ou conbecido, expresso ou realmente nomeado; 0 que nato E, não o pode. 
Esse princípio me faz voltar à Universidade de Princeton quando, em 1945, preparava minha tese de doutorado sob a orientaçăo de Wolfgang Pauli. Naquele ano, no Fine-Hall, Departamento de Matemática e Física Teórica da Universidade, o matemático francês Jacques Hadamard realizava um seminário sobre a psicologia da invenção matemática. Durante a discussão, a seguinte pergunta foi feita por Einstein: quando o senhor cria, quando o senhor tem uma nova idéia, estaria ela associada necessariamente a uma palavra? Vemos que Einstein, como Parmênides, fazendo essa pergunta, estava preocupado com as relaçóes entre o real, o pensamento e a linguagem. Segundo Parmênides, ser e ser pensado sấo a mesma coisa.

"Thought is uttered in names that are true, i.e., names of what really is." Apenas aquilo que é pode ser pensado ou realmente nomeado; e apenas aquilo que pode ser pensado pode ser.

Naturalmente, o ponto fraco do sistema de Parmênides é que seus postulados rejeitam o mundo, a variedade das coisas resultante do Um. Essa variedade, assim como nascer, tornar-se, mudança, movimento, é, segundo ele, irreal. De sua filosofia restou entretanto o conceito de substancia fundamental permanente, de uma realidade indestrutível.

Os sucessores de Parmênides deviam restabelecer a questáo da realidade das coisas, da pluralidade, do mundo que nos é dado por nossas percepçóes e que, para Parmênides, seria apenas uma ilusão, visto que náo poderia ser subtraído da unidade. Empédocles admitiu que o Um é sempre vários, visto que seria constituído de quatro partes, uma mistura de quatro elementos diferentes que podem deslocar-se - os quatro elementos de Anaximandro, o fogo, o ar, a água, e a terra. Esses elementos sáo eternos, imutáveis, movem-se uns através dos outros assim como para Parmênides, o vazio também náo existe para Empédocles. Para Anaxágoras, se os elementos năo podem ser criados ou perecer, o aparecimento de uma coisa é o resultado de uma nova combinaçáo dos quatro elementos, seu desaparecimento resulta de uma dissolução de uma dada combinação. Assim, Empédocles e Anaxágoras substituíram o monismo absoluto de Parmênides por uma pluralidade de elementos permanentes que podem ter movimento e, dessa forma, ocasionar mudanças.

\section{A cosmogonia de Platão}

A cosmogonia de Platão está exposta em seu diálogo Timeu: o que é permanente, imutável, é adquirido pela inteligência; o que está em transformação é adquirido pelo que ele chama de opinião. Visto que o 
mundo é apreendido por nossas sensaçóes, ele não pode ser eterno, deve ter sido criado por Deus.

Os quatro elementos - fogo, ar, água, terra - sáo representados por números que mantêm uma certa proporção entre si. $O$ tempo e $O$ céu foram criados juntos. Mas os verdadeiros elementos primordiais náo são os quatro elementos citados acima; são, antes, duas espécies de triângulo retângulo, sendo um a metade de um quadrado e o outro a metade de um triângulo eqüilátero; essas sáo as mais belas formas. Devido à sua beleza, Deus os utilizou para constituir a matéria. Cada átomo de um dos quatro elementos é um sólido regular (conexo) construído a partir desses triângulos: os átomos da terra sáo cubos, os do fogo são tetraedros, os do ar, octaedros, os da água, icosaedros. O quinto, o dodecaedro, não pode ser construído pelos dois triângulos de Platáo - mas sim a partir de pentágonos regulares. Segundo Platão, Deus o utilizou no esquema do Universo - que seria, apesar dessa afirmaçăo, esférico.

No Teeteto, Platão critica a concepģão segundo a qual o conhecimento é a mesma coisa que a percepçáo. Apenas o pensamento pode nos fazer conhecer o que existe, ou seja, as idéias; o conhecimento consiste, portanto, em reflexóes, e não, de forma alguma, em impressóes e percepçóes.

Em Platáo, como em Pitágoras, encontramos, entáo, as origens da concepçáo segundo a qual a matemática descreve o mundo, uma concepçáo que será incorporada na física com Galileu.

\section{A física de Aristóteles}

Como sabemos, a física e a cosmogonia de Aristóteles não contribuíram para a ciência moderna. Mas têm uma importância histórica indubitável, porque dominaram as especulaçóes sobre o mundo até $\mathrm{Ga}$ lileu, até o século XVII. Segundo Aristóteles, existem duas espécies de movimento: o dos corpos terrestres e o dos corpos celestes. $O$ céu consiste em dez esferas concêntricas, tendo a esfera da lua o menor raio. No interior dessa esfera, tudo o que está sob a Lua está sujeito à corrupçáo e à desintegraçáo. Fora da esfera da Lua, tudo é indestrutível.

O movimento dos corpos terrestres se produz como o dos animais, com uma finalidade. Os corpos celestes, ao contrário, sáo caracterizados pela regularidade de seus movimentos, produzidos pela vontade de um Deus. Além das esferas de Mercúrio, de Vênus, do Sol, de Marte, de Júpiter e de Saturno, existe a esfera das estrelas fixas, o Primum Mobile. 
Além do Primum Mobile, não há movimento, tempo ou lugares. Deus, o Motor Primordial, ele próprio imóvel, produz a rotaçáo do Primum Mobile que transmite seu movimento para a esfera das estrelas fixas e esse movimento é transmitido até a esfera da Lua: essa é a concepção do mundo cristão da Idade Média, herdada de Aristóteles e apresentada no Paraiso de Dante. Quanto à física de Aristóteles, era um corpo teórico logicamente coerente e construído para descrever os movimentos de nossa experiência de todos os dias: um corpo pesado cai para baixo; a chama se move para cima. Segundo Aristóteles, acima de tudo, cada corpo tem um lugar determinado no mundo e opóe resistência a qualquer esforço que tende a retirá-lo daquele lugar. Daí, a idéia de movimento como resultado de uma violência e, uma vez cessada a violência, os corpos em movimento voltam ao repouso. Em termos modernos, podemos dizer que a dinâmica de Aristóteles define a força como sendo a impulsão. A equação de movimento de Aristóteles é a seguinte:

$$
\vec{F}=\mu \frac{d \vec{x}}{d t}
$$

onde $\mu$ seria a massa do corpo. Se $\vec{F}=0, \vec{x}=\vec{x}_{0}$, o corpo está em repouso no lugar definido pelo vetor $\vec{x}_{0}$.

Segundo Aristóteles, o vazio não existe. No vazio, assim como no espaço geométrico, não existem lugares nem direçóes privilegiadas. Consequientemente, as figuras geométricas năo podem descrever os corpos materiais: a física não pode ser descrita pela matemática. Seria até mesmo perigoso, segundo Aristóteles, misturar física e geometria, aplicar o raciocínio matemático ao estudo da realidade física.

\section{A crítica de Aristóteles}

Os críticos e os adversários da dinâmica de Aristóteles chamavam a atenção para o fato de que o movimento continua, assim que cessou a força, ação motriz que lhe deu origem. Dentre eles, citemos Jean Philopon, Jean Buridan e Nicole Oresme, da Escola dos Nominalistas de Paris (século XIV), Leonardo da Vinci, Benedetti e Galileu (séculos XVI e XVII).

Essa crítica produziu a teoria do impetus: ao invés de considerar o ar ao mesmo tempo como resistência e motor dos movimentos, por que não admitir que alguma coisa é transmitida àquilo que se move pela ação motriz, alguma coisa que foi, entáo, denominada virtus motiva, virtus 


\section{I S C O R S I \\ DIMOSTRAZIONI \\ M A T E M A T I C H E, intorno a due nuoue fienze \\ Artenenti alla \\ Mecanica \&i Movimenti Locali, delsignor \\ CA L I L E GA LI LEI L I N C E O. Filolofo c Matematico primario del Serenilimo Criand Duca di Tofcana. \\ con una Appendicedelcentrodigranira d'alcuni solidi.}

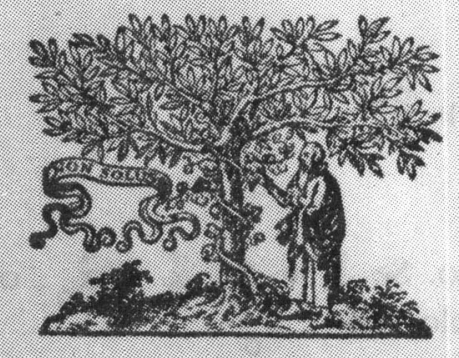

I N L E I D A,

Apprefro gli Ellevirii. M. D. C. xxxvin.
Fac-simile da capa do limo de Galibu, extratio de "Cidncia

Hoje", pol. 9/n? 50

impressa, impetus, impetus impressus, que faz com que o movimento continue? Durante mil anos, essa noção de impetus permaneceu ambígua e confusa.

\section{A revolução cristalizada em Galileu}

Uma revoluçáo na concepçáo física do mundo, a formulação de uma nova linguagem e de uma nova filosofia foram necessárias para a eclosão da física moderna. A concepçáo aristotélica e medieval do Cosmo finito, constituído de um certo número de esferas hierarquicamente ordenada teve de ser substituída pela idéia de um Cosmo aberto, um Universo infinito.

Se no mundo de Aristóteles havia lugar para leis aplicáveis ao Céu e leis descritivas apenas das coisas da Terra, no novo sistema do mundo existiria apenas um único tipo de leis, as leis físicas universais, válidas em toda a parte (Quadro V). 
O novo sistema do mundo, que adquiriu forma mais precisa a partir de Galileu, estabeleceu, então, a identificação do espaço físico com o espaço infinito da geometria euclidiana, onde é possível pensar um corpo isolado do resto do Universo, ingrediente do princípio da inércia. O movimento e o repouso são, então, considerados como estados em um mesmo nível existencial, ontológico.

Em linguagem moderna, pode-se expressar a equivalência ontológica dos estados de repouso e de movimento retilíneo e uniforme dizendo-se que a mecânica clássica admite o grupo de Galileu: já que o repouso não precisa de nenhuma causa para se manter, o mesmo acontece com um movimento retilíneo e uniforme que se deduz do estado de repouso pela aplicação de uma transformação desse grupo.

\section{Quadro V}

"Trazemos ao mais antigo assunto um conhecimento absolutamente novo. Talvez - não exista na natureza nada de anterior ao movimento, e os tratados que lhe foram consagrados pelos filósofos não são pequenos em número, nem em volume; entretanto, entre suas propriedades, numerosas e dignas de ser conhecidas, estáo aquelas que, pelo que eu conheço, ainda não foram nem observadas como, por exemplo, o fato de que o movimento natural dos graves, em queda livre, é continuamente acelerado; segundo com qual proporçáo, todavia, se produz essa aceleraçáo, não se estabeleceu até aqui: ninguém, que eu saiba, demonstrou que os espaços percorridos em termos iguais por um móvel partindo do repouso têm, entre si, mesma relaçáo que os números ímpares sucessivos a partir da unidade. Observou-se que os corpos lançados, ou projéteis, descrevem uma curva de um certo tipo; mas, que essa curva seja uma parábola, ninguém o pôs em evidência. Fatos como esse, e outros não menos numerosos e dignos de ser conhecidos, é que seráo demonstrados para, desta forma - o que considero muito mais importante - dar acesso a uma ciência tão vasta quanto eminente, cujo início está marcado pelos meus próprios trabalhos e cujas partes mais recônditas seráo exploradas por espíritos mais perspicazes que o meu."

GALIEEU, Discours concernante deux sciences nouvelles, troisième journée (N.T.: Discurso sobre duas ciências novas, terceira jornada). 
Em 1543, Copérnico retirou a Terra de seu repouso abaixo do Paraíso e lançou-a ao espaço. Entre 1609 e 1619, Kepler formulou as leis de movimento dos corpos celestes, destruindo, portanto, a hierarquia das esferas do Cosmo fechado de Aristóteles. E Galileu, observando o Céu com os primeiros telescópios, descobriu novos corpos celestes náo previstos no modelo aristotélico preestabelecido por Deus. Descobrindo o princípio da inércia, assim como a lei da queda livre dos corpos, Galileu abriu o caminho para a grande síntese de Newton e, como Pitágoras e Platáo, declarou que o livro da natureza está escrito em linguagem matemática.

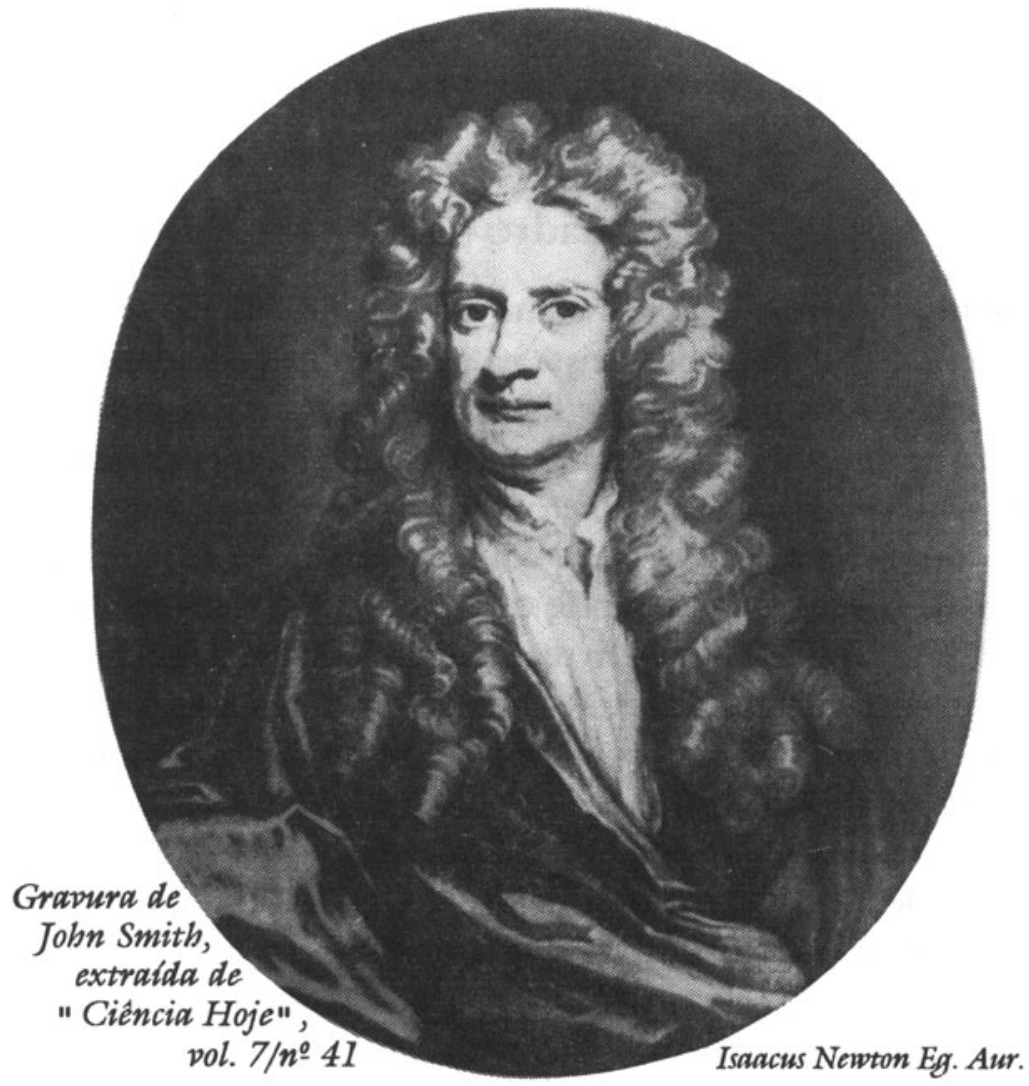

O sistema do mundo newtoniano

A física moderna adquiriu, então, sua primeira forma com o sistema de Newton, em seus Princtpios Matemáticos da Filosofia Natural. Sua equação do movimento, que estabelece que a força é o produto da massa do corpo por sua aceleração, esteve na base da física até a descoberta da mecânica quântica em 1925. Sua lei de gravitação universal foi a intuição de um gênio que completou a tarefa de Galileu assimilando os movimentos dos corpos terrestres aos movimentos dos corpos celestes submetidos a uma mesma força, a força de gravitação. $O$ fato de que essa 
força fosse transmitida instantaneamente - uma ação à distância - era certamente um mistério que inquietou o próprio Newton. Os sucessos da mecânica newtoniana, os trabalhos de pesquisa de homens como Maupertuis, D'Alembertt, Euler, Lagrange, Laplace, fizeram esquecer a dificuldade de interpretação da força de gravitação. Segundo Ernest Mach, a atração gravitacional perdeu seu caráter de incompreensão extra. ordindria para ter apenas uma incompreensáo ordinária.

No șéculo XVIII, graças à filosofia de Locke e às cartas filosóficas de Voltaire, o newtoniano se tornou o dogma do sistema físico do mundo.

O sistema de Newton incorporou as idéias atômicas. Pois, como se pode notar, não mencionei até aqui as geniais intuições dos atomistas gregos do século IV a.C., de Leucipo e de Demócrito, influenciados pelo monismo de Parmênides e de Zenáo. Talvez, com a preocupação de fazer uma síntese entre os sistemas de Parmênides e de Empédocles, eles postularam que todas as coisas são compostas por átomos que se movem incessantemente no vazio, no espaço vazio; que os átomos sáo indivisíveis, que sempre estiveram em movimento e que estarāo sempre em movimento. Os atomistas admitiam o determinismo: nada pode acontecer por acaso. O sistema filosófico de Leucipo e de Demócrito foi retomado por Gassendi no começo do século XVII; ele é um dos inspiradores da física moderna.

Está claro que essa concepção se associava harmoniosamente ao sistema do mundo de Galileu e Newton, sendo as leis do movimento de Newton responsáveis pelo movimento dos átomos (Quadros VI e VII).

\section{Quadro VI}

"All these things being consider'd, it seems probable to me that God in the beginning form'd Matter in solid, massy, hard, impenetrable, moveable Particles, of such Sizes and Figures, and with such other properties, and in such Proportion to Space, as most conduced to the End for which he formed them; and that these primitive Particles being Solids, are incomparably harder than any porous bodies compounded of them; even so very hard, as never to wear or break in pieces; no ordinary Power being able to divide what God himself made one in the first creation."

Isaac NEWTON, Opticks. 


\section{Quadro VII}

"In the beginning (if there was such a thing) God created Newton's laws or motion together with the necessary masses and forces. This is all; everything beyond this follows from the development of appropriate mathematical methods by means of reduction."

EINSTEIN, in Albert EINSTEIN, Philosopher-Scientist.

(Devemos destacar o físico inglês Robert Boyle, que tentou opor o atomismo ao sistema de Galileu-Newton: em vez de ser escrito em linguagem matemática, o livro da Natureza seria um romance imaginado em termos corpusculares.)

Pela primeira vez, um antigo dualismo conceitual, que consistiria na oposiçâo entre as noçóes de um e de vários adquire uma forma explícita e precisa do objeto material e de seu movimento e que agora se exprime no dualismo matéria-força (Quadro VIII).

\section{A noção de campo}

Chegamos agora a uma outra noçáo fundamental da física moderna, a noçáo de campo, resultante dos trabalhos experimentais sobre a eletricidade e o magnetismo, e cuja forma final devemos a Faraday, Maxwell e Lorentz. A união da óptica com a eletricidade e o magnetismo, baseada nas pesquisas de Galvani e Volta, de Oersted e Ampère, foi a grande síntese concluída pelas equaçóes de Maxwell. $\mathrm{Na}$ época, muitos físicos, impregnados pela imagem mecânica do mundo conforme Newton, tentarão interpretar essas equações segundo certos modelos mecânicos. Heinrich Hertz, um dos mestres desses ensaios, afirma em 1894: "Todos os físicos concordam em considerar que a tarefa da física é reduzir os fenômenos naturais às leis elementares da mecânica".

\begin{tabular}{|cc|}
\hline \multicolumn{2}{c|}{$\begin{array}{c}\text { Quadro VIII } \\
\text { Dualismo newtoniano } \\
\text { Matéria-Força }\end{array}$} \\
$\begin{array}{cc}\text { Matéria } \\
\text { Equação do Movimento }\end{array}$ \\
$m \frac{\mathrm{d}^{2} \overrightarrow{\mathrm{x}}}{\mathrm{dt}^{2}}=\overrightarrow{\mathrm{F}}$ & $\begin{array}{c}\text { Força } \\
\text { Equação da Força }\end{array}$ \\
\hline
\end{tabular}

A reaçáo a essas tentativas foi, dez anos mais tarde, expressa nesta frase de W. Kauffmann: "Em lugar de todas essas tentativas sem suces- 
so, visando principalmente a descrever mecanicamente os fenômenos elétricos e magnéticos, não poderíamos reduzir a mecânica ao estudo das reaçóes elétricas? Se todos os átomos da matéria consistem em um aglomerado de elétrons (segundo a tese de J. J. Thomson), sua teoria resulta portanto dessa estrutura".

No Quadro IX, é Einstein que descreve o caráter revolucionário da teoria de Maxwell; ele compara o papel de Faraday e Maxwell ao de Galileu e Newton. E, no Quadro X, Boltzmann caracteriza a noção de modelo em física moderna.

No começo do século XX, a dualidade matéria-força era expressa, de um lado pelas equaçóes de Lorentz sobre os elétrons e, de um outro lado, pelas equaçóes de Maxwell sobre o campo eletromagnético que determina a força que age sobre esses elétrons (Quadro XI).

\section{Quadro IX}

" The most fascinating subject at the time that I was a student was Maxwell's theory. What made this theory appear revolutionary was the transition from forces at a distance to field as fundamental variables. The incorporation of optics into the theory of eletromagnetism, whit its relations of the speed of light to the eletric and magnetic absolute system of units as well as the relation of the refraction coefficient to the dielectric constant, the qualitative relation between the reflection coefficient and the metallic condictivity of the body - it was like a revelation."

EINSTEIN, Loc. cit.

\section{Quadro X}

As equaçóes diferenciais da fenomenologia físico-matemática nada mais são que regras para formar e combinar números e conceitos geométricos; por sua vez, estes sáo apenas imagens mentais com as quais as aparências são preditas. Em todo caso, parece que, de um conjunto global de fatos, jamais podemos ter uma descrição direta, mas, antes, uma descriçáo mental. Consequientemente, náo devemos concordar com Ostwald "não façam nenhuma imagem", mas sim "introduzam nessa imagem o menor número possível de elementos arbitrários".

L. BOLTZMANN, Ann. Phys. un Chemie 60, 231 (1987). 
Chegamos, assim, ao final do século XIX e começo do XX, com a descoberta do elétron por J. J. Thomson. Thomson, com a teoria de Lorentz que procurou descrever a matéria e seus átomos a partir de sua estrutura eletrônica.

Segundo vários físicos dessa época, as leis fundamentais da Natureza eram bem conhecidas; aos futuros físicos, restaria apenas aplicá-las aos diversos fenômenos para descrevê-los - um trabalho não mais de ciência pura, mas, antes, de ciência aplicada, de tecnologia.

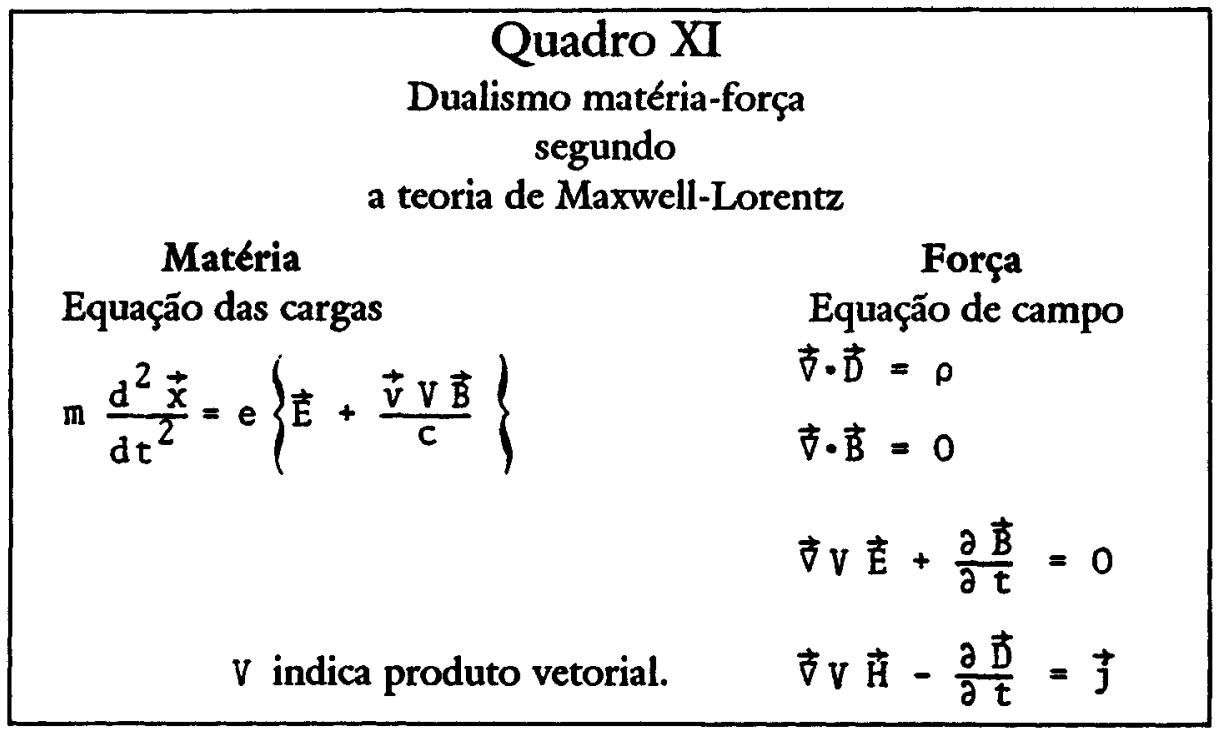

Planck, Einstein, Lorentz, Poincaré

Foi exatamente nesse momento que dois homens de talento descobriram as bases de suas novas teorias, revolucionárias em relação à física clássica, e que somente elas poderiam explicar certos fenômenos novos que escapavam à explicaçáo pelas idéias estabelecidas.

Como se sabe, Planck empenhou-se no problema da distribuição espectral da energia da radiaçáo em equilíbrio térmico em uma cavidade fechada e opaca - o problema da radiaçáo do corpo negro - e a soluçáo que encontrou levou-o a estabelecer os fundamentos do modelo quântico de Bohr, modelo que, por sua vez, encontrou seus fundamentos matemáticos em 1925, na mecânica quântica.

Se o trabalho de Planck, em 1900, rompeu, apesar de suas aspirações, com a física clássica, foi consolidado por Einstein em 1905, com sua teoria dos fótons.

Ainda em 1905, como todos sabem, Einstein lançou as bases da teoria da relatividade restrita. 
Tomou-se conhecimento, nessa época, de que as equaçóes de Maxwell e as equaçóes de Lorentz não eram invariantes em relação ao grupo de Galileu (pois não admitiam o grupo da mecânica clássica). Enquanto esse grupo implica uma velocidade da luz que depende do estado do movimento da fonte, as equaçóes de Maxwell implicam que a velocidade da luz no vazio náo tem essa dependência. Enquanto Lorentz buscou fórmulas de transformação de coordenadas que implicariam uma contração das distâncias necessárias para explicar certas experiências (como a de Michelson-Morley), Poincaré, como bom matemático que era, estabeleceu as transformaçóes lineares e não-homogêneas das coordenadas espaciais e do tempo, que deixam invariantes as equaçóes de Maxwell.

\section{Einstein e a física relativística}

O mérito de Einstein foi resolver essas questóes enquanto físico. Ele mostrou que a invariância da simultaneidade de fenômenos distantes no espaço ordinário acarreta a existência de sinais com uma velocidade infinita, uma hipótese, aliás, da mecânica clássica. Se abandonarmos essa hipótese, inspirada pela teoria dos campos de Maxwell e se postularmos a existência de uma velocidade de sinal luminoso finita, máxima, o tempo deve, então, se transformar, exatamente como as coordenadas, quando mudamos de sistema de referência. Ele chegou, pois, às mesmas fórmulas não-homogêneas do grupo de Lorentz, estabelecidas matematicamente por Poincaré e essencialmente descobertas por Lorentz o grupo de transformação que hoje chamamos grupo não-homogêneo de Lorentz ou grupo de Poincaré. O grande mérito de Einstein foi discutir a fundo, e com extraordinária eloqüência, o significado físico profundo do grupo de Poincaré e de suas conseqüências. Devemos-lhe, ainda, a idéia de interrogar-se acerca das simetrias como elemento fundamental de uma teoria, ao invés de procurar deduzi-las das equaçóes do movimento, se estas forem conhecidas. Lançou, assim, as bases físicas da teoria da relatividade e, em particular, estabeleceu a famosa relação de equivalência entre massa e energia - proposta com profundas implicaçóes filosóficas e que teve espetacular demonstraçáo na física nuclear e na física das partículas.

O princípio de relatividade restrita afirma que é impossível, através de experiências físicas realizadas dentro de um laboratório fechado, dizer onde esse laboratório se situa no espaço de três dimensóes, qual é a orientação de sentido dos três eixos nesse espaço; é, ainda, impossível distinguir uma origem absoluta do tempo inicial das experiências realizadas dentro do laboratório e não se pode detectar uma velocidade cons- 
tante do laboratório - não se sabe se ele está em repouso ou em movimento em relação a um outro laboratório. Esse princípio, evidentemente, pressupóe que estamos mergulhados em uma parte do Univerșo onde essas condiçóes se realizam. Um laboratório fechado, situado na fronteira do Universo, caso este fosse fechado, deveria ser capaz de detectar sua posição.

Foi este o grande mérito de $\mathrm{H}$. Minkowski: introduzir um formalismo baseado em cálculo tensorial quadrimensional, que se revelou a forma natural da teoria da relatividade e, segundo o qual, as transformaçóes de Poincaré traduzem uma espécie de rotaçáo seguida de uma translaçáo no espaço-tempo - espaço constituído pelo tempo e pelas três coordenadas espaciais. Nesse formalismo, as equaçóes relativísticas revestem-se de uma forma concisa e elegante (Quadro XII).

Da teoria da relatividade restrita, herdamos, portanto, o decisivo estabelecimento da noção de simetria das leis físicas. Se as leis físicas estabelecem relaçóes entre variáveis associadas a objetos e a fenômenos, o princípio da relatividade exerce um controle sobre as leis físicas, tendo o caráter de uma superlei. E, dessa teoria, resulta a noçáo de relatividade de simultaneidade e das distâncias, da energia e de impulsáo, dos campos elétricos e magnéticos.

\section{Einstein e a teoria relativística da gravitação}

Após a conclusão da teoria de relatividade, Einstein concentrou seus esforços em generalizá-la, ou seja, em responder à pergunta feita por Ernest Mach: por que os sistemas inerciais se distinguem fisicamente de todos os outros sistemas de coordenadas? Será que a independência das leis da física em relação ao estado de movimento do laboratório deve ser restrita aos movimentos retilíneos e uniformes? Ao mesmo tempo, Einstein tentava tratar o campo de gravitação segundo a teoria da relatividade restrita. Enquanto a teoria de Newton era naturalmente náo-relativística (Quadro VII), as equaçóes do campo eletromagnético e as equaçóes dos elétrons clássicos eram incorporadas de uma maneira natural no quadro da relatividade restrita (Quadro XII). A tentativa de generalizar a equaçáo de Poisson em uma equaçáo de D'Alembert sendo o campo e sua fonte escalares, invariantes relativísticas - não obteve sucesso, inclusive, porque a igualdade "massa de inércia-massa de gravitação" não podia ser nela estabelecida de maneira simples e porque a densidade de massa não é um componente de um quadrivetor nem um escalar. 


\section{Quadro XII}

\section{DUALIDADE MATÉRIA-FORÇA}

na teoria de Maxwell-Lorentz

segundo

a relatividade restrita

Matéria

Equação das cargas
Força

Equação do campo

$$
\left\{\begin{array}{l}
m_{0} c^{2} \frac{d^{2} z^{\mu}}{d s^{2}}=-e F^{\mu \nu}(z) \frac{d z v}{d s} \\
z^{\mu}=z^{\mu}(s) \\
d s^{2}=d z^{\mu} d z_{\mu} \\
F^{\mu \nu}=\partial^{\nu} A^{\mu}-\partial^{\mu} A^{\nu}
\end{array}\right.
$$$$
j^{\mu}(x)=\int \frac{d z^{\mu}}{d s} \delta(4)(x-z(s)) d s
$$

Essas equações são invariantes em relação ao grupo de Poincaré

onde

$$
x^{\mu \mu}=a^{\mu}+e^{\mu}{ }_{\nu} x^{\nu}
$$

$\mathrm{g}_{\alpha \beta}$ é a métrica do espaço:

$$
\ell_{\alpha}^{\mu} g_{\mu \nu} \ell_{B}^{\nu}=g_{\alpha \xi}
$$

$$
d s^{2}=g_{\mu \nu} d x^{\mu} d x^{\nu}
$$

O espaço se transforma no tempo e vice-versa, como vemos na fórmula de boost de Lorentz:

$$
\begin{aligned}
& x^{\prime}=\frac{x-v t}{\sqrt{1-v^{2} / c^{2}}}, y^{\prime}=y, z^{\prime}=z \\
& t^{\prime}=\frac{t-v / c^{2} x}{\sqrt{1-v^{2} / c^{2}}}
\end{aligned}
$$

uma afirmação que se estende ao duos energia-impulsão, densidade de corrente-vetor corrente, que constituem quadrivetores. $O$ caráter relativo do valor das grandezas físicas (que apenas têm sentido se especificarmos o estado do movimento do laboratório e do sistema objeto-aparelho) é acompanhado de proposiçóes que têm um caráter absoluto - as leis físicas que estabelecem a correlação entre essas medidas são invariantes em relação ao grupo de Poincaré, válidas, portanto, em todos os sistemas inerciaisabsolutos, nesse sentido. 
A comparação das forças ditas fictícias (Coriolis e centrifugas) em um sistema em rotação com uma força de gravitação homogênea, e a possível eliminaçáo delas por uma escolha apropriada de sistemas de referência, conduziu Einstein, nos dois casos, à descoberta do princípio de equivalência. Eis o enunciado desse princípio: é impossível, por meio de experiências físicas realizadas dentro de um laboratório fechado, dizer se esse sistema está em movimento uniformemente acelerado com uma aceleraçáo $-\vec{\gamma}$, para cima, sob nenhum campo de gravitação, ou se, pelo contrário, o laboratório é um sistema de inércia sobre o qual age um campo de gravitaçáo homogêneo, para baixo, com os corpos caindo com aceleraçáo $\overrightarrow{\mathbf{g}}$, onde $|\vec{\gamma}|=|\overrightarrow{\mathbf{g}}|$. Esse princípio só é possível se houver uma igualdade exata entre a massa de inércia e a massa gravitacional.

A partir dessas reflexóes sobre o elevador que cai em queda livre, Einstein recorreu ao formalismo de Minkowski para dizer que, em geral, quando subordinamos a distância infinitesimal entre dois pontos a um sistema arbitrário, essa distância se expressa segundo a equaçáo abaixo, onde as funçóes $g_{\mu \nu}(x)$, de ponto e do tempo, são os componentes de um tensor simétrico. Graças a Marcel Grosmann, Einstein conheceu a geometria de Riemann e o cálculo diferencial absoluto de Ricci e Levi Civita. E sua grande intuiçáo criadora o fez erigir como postulado que o campo de gravitafáto to tensor $g_{\mu \nu}(x)$. Ao mesmo tempo, ele pesquisou as variáveis e as equaçóes do espaço físico. Usando suas próprias palavras: "Conhecemos, com certeza, um caso especial, o de um 'espaço livre de campo' tal como é considerado na teoria da relatividade restrita" . Esse tipo de espaço é caracterizado pela distância elementar $d s^{2}=\left(d x^{0}\right)^{2}-\left(d x^{1}\right)^{2}-\left(d x^{2}\right)^{2}-\left(d x^{3}\right)^{2} \quad$. Dentro de um sistema arbitrário, essa quantidade pode ser assim escrita:

$$
d s^{2}=g_{\mu \nu}(x) d x^{\mu} d x
$$

"Se, após essa transformaçăo, as derivadas primeiras de $g_{\mu \nu}(x)$ não se anularem, existe um campo gravitacional em relaçăo a esse sistema..."

Visto que a densidade de massa, fonte do campo de Poisson, é equivalente a uma densidade de energia segundo a relatividade restrita e como esta a caracteriza como um dos componentes de um tensor, o tensor energia-pulsão $T_{\mu \nu}$, fica claro que a nova equaçáo deve conter $\mathrm{T}_{\mu \nu}$ como fonte. A parte diferencial que substituiria o laplaciano do postulado newtoniano deveria, entáo, ser um tensor de segunda ordem, 
contendo derivadas segundas do potencial gravitacional $g_{\mu \nu}$, assim como de suas derivadas primeiras, uma equação do tipo:

$$
B_{\mu \nu}\left(g_{\alpha \beta}, \partial_{\lambda} g_{\alpha \beta}, \partial_{\lambda} \partial_{\nu} g_{\alpha \beta}\right)=K T_{\mu \nu}
$$

Após vários anos de pesquisas, de tentativas e erros, Einstein finalmente descobriu sua famosa equaçáo em 1915. Ele identificou $g_{\mu \nu}$ ao campo de gravitaçáo e, na geometria de Riemann, encontrou as ferramentas para descobrir a forma de $B_{\mu \nu}$. Trabalhando praticamente sozinho, conduzido por sua excepcional imaginação, foi levado a aplicar o cálculo diferencial absoluto a seu mundo físico de quatro dimensóes; juntamente com a geometria de Riemann, esse cálculo lhe forneceu os elementos geométricos para sua equação do campo gravitacional.

Ao longo de suas pesquisas, uma intuição tomava corpo em seu espírito; de acordo com ela, o espaço físico está dinamicamente associado à gravitação, a dinâmica gravitacional é descrita pela geometria do espaço. Como encontrar essas variáveis e as equaçōes que traduzem matematicamente essa intuição? O Quadro XII nos apresenta uma síntese das equaçóes da teoria. É de fundamental importância a condição que, em uma vizinhança suficientemente pequena, possamos estabelecer um sistema de referência (tangencial) localmente inercial, ou seja, onde desapareçam localmente os efeitos da gravitaçáo. É a forma geral do princípio de equivalência. Desse sistema, podemos, entáo, passar a um outro igualmente inercial por intermédio de uma transformaçáo de Lorentz local. É desse modo que introduzimos a noção de espinor $\psi(x)$ em relatividade geral: invariante em relação a uma transformação geral de coordenadas, mas se transformando como espinor de Dirac sob as transformaçóes locais de Lorentz.

A teoria relativista da gravitação previu efeitos que foram observados de acordo com a predição, entre os quais o deslocamento do periélio de Mercúrio, a dependência do andamento dos relógios e das distâncias em relaçáo à gravitação. É ela a base da cosmologia moderna. Outros efeitos, tais como a existência de singularidades, os buracos negros, as ondas gravitacionais, são objeto de pesquisa e estudo.

A relatividade geral imprimiu em Einstein uma concepção matemática do conhecimento físico, evocando, de certa maneira, as concepçóes de Pitágoras e Platáo. 


\section{Quadro XIII}

EQUAÇĀO DO CAMPO GRAVITACIONAL DE EINSTEIN

Transformaçóes gerais das coordenadas

$$
x^{\mu \nu}=f^{\mu}\left(x^{0}, x^{1}, x^{2}, x^{3}\right) \quad y=0,1,2,3
$$

de jacobiano

$j=\left|\frac{\partial f^{\mu}}{\partial x^{\nu}}\right| \neq 0$

A partir da relaçáo diferencial

$$
d x^{\prime \nu}=\frac{\partial f^{\mu}}{\partial x^{\nu}} d x^{\nu}
$$

postula-se a noção de vetor

$$
A^{\prime}\left(x^{\prime}\right)=\frac{\partial f^{\mu}}{\partial x^{\nu}} A^{\nu}(x)
$$

A distância elementar é

$$
d s^{2}=g_{\mu \nu}(x) d x^{\mu} d x^{\nu}
$$

a cada ponto associa-se $g^{\alpha \beta}(x)$

$$
g^{\alpha \beta}(x) g_{B \lambda}(x)=\delta_{\lambda}^{\alpha}
$$

esses tensores fazem elevar e descer os índices:

$B_{\mu^{2}}(x)=g_{\mu \nu}(x) B^{\nu}(x)$

onde

$$
B^{\prime}{ }_{\mu}\left(x^{\prime}\right) A^{\prime \mu}\left(x^{\prime}\right)=B_{\alpha}(x) A^{\alpha}(x)
$$

conduz a

$$
B_{\mu}^{\prime}\left(x^{\prime}\right)=\frac{\partial x^{\nu}}{\partial x^{\prime \mu}} B_{\nu}(x)
$$

Tensor em geral:

$$
\begin{aligned}
& T^{{ }^{\mu_{j}} \cdots \mu_{m}} \quad\left(x^{\prime}\right)= \\
& v_{1} \ldots v_{n}
\end{aligned}
$$

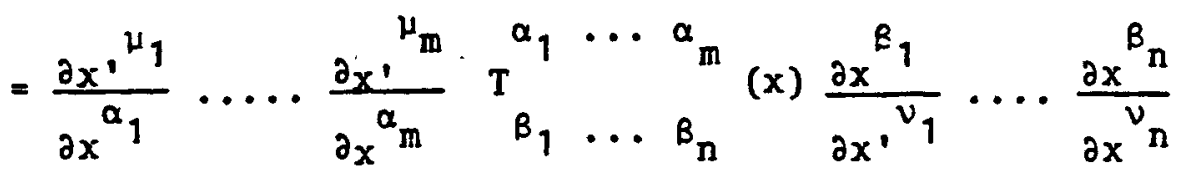


Como a derivada de um vetor não conduz a um tensor, é preciso substituí-la por uma derivada covariante tal que:

$\nabla_{j}^{\prime} F^{\prime \alpha}\left(x^{\prime}\right)=\frac{\partial x^{\nu}}{\partial x^{\prime \mu}} \frac{\partial x^{\prime \alpha}}{\partial x^{\beta}} \nabla_{\nu} F^{\beta}(x)$

e se exprime em termos da afinidade $\Gamma_{\mu \nu}^{\alpha}(x)$

$\nabla_{j} F^{\alpha}=\partial_{p} F^{\alpha}+\Gamma_{j \nu}^{\alpha} F^{\nu}$

$\nabla_{F} F_{\alpha}=\partial_{\mu} F_{\alpha}-\Gamma_{\mu \alpha}^{\nu} F_{\nu}$

A afinidade desempenha o papel de um campo de calibre e se exprime em funçáo do potencial gravitacional $g_{\mu \nu}$ :

$\Gamma_{\mu \nu}^{\alpha}(x)=\frac{1}{2} g^{\alpha \lambda}\left(\partial_{\mu} g_{\lambda \nu}+\partial_{\nu} g_{\lambda \mu}-\partial_{\lambda} g_{\mu \nu}\right)$

A álgebra das derivadas covariantes conduz ao tensor de Riemann, tensor de curvatura:

$\left[\nabla_{\mu}, \nabla_{\nu}\right] F_{\alpha}(x) \equiv R_{\alpha \cup \mu}^{\lambda} F_{\lambda}(x)$

onde

$R_{\alpha \nu \mu}^{\lambda}=\partial_{\nu} \Gamma_{\alpha \mu}^{\lambda}-\partial_{\mu} \Gamma_{\alpha \nu}^{\lambda}+\Gamma_{\alpha \mu}^{\eta} \Gamma_{\eta \nu}^{\lambda}-\Gamma_{\alpha \nu}^{\eta} \Gamma_{n \mu}^{\lambda}$

é a contraçáo deste tensor

$R_{\mu \nu}=R_{\mu \alpha \nu}^{\lambda} \delta_{\lambda}^{\alpha}$

que é único, que dá lugar ao tensor $R_{\mu \nu}$.

A combinaçáo

$G_{\mu \nu}=R_{\mu \nu}-\frac{1}{2} g_{\mu \nu} R$

tem, então, a importante propriedade de possuir uma divergência covariante nula, propriedade que impomos ao tensor energia-impulsão (que se conserva na ausência de um campo de gravitação). De onde a equação postulada por Einstein em 1915

$R_{\mu \nu}-\frac{1}{2} g_{\mu \nu} R=-K T_{\mu \nu}$

onde $T_{\mu \nu}$ é a densidade de energia-impulsão da matéria, que nela entra como a fonte do campo de gravitação. Essas equaçóes não-lineares foram objeto de pesquisa durante décadas, tanto pelo próprio Einstein, como por seus colaboradores.

Especialmente Einstein e Léopold Infeld mostraram que a equação de movimento de uma partícula clássica em um campo de gravitação, a saber a equaçáo da geodésica:

$\frac{d^{2} z^{\mu}}{d s^{2}}+\Gamma_{\alpha \beta}^{\mu} \frac{d z^{\alpha}}{d s} \frac{d z^{\beta}}{d s}=0$

está contida nas equaçóes do campo: uma sintese matéria-forga pela primeira vez concluida em física. 
Uma síntese similar é concluída nas teorias dos campos de calibre. $\mathrm{O}$ postulado segundo o qual todas as interaçóes sáo descritas por tais campos leva a uma síntese matéria-força, visto que os campos de calibre são exigidos pelo princípio segundo o qual a equação da matéria é invariante em relação a transformações de fase local pertencentes a um certo grupo.

Eis o que escreve em um ensaio sobre o método da física tebrica: "Os físicos (do tempo de Newton) estavam antes, em sua maioria, imbuídos pela idéia de que os conceitos fundamentais e as leis fundamentais da física não são, no sentido lógico, invençōes livres do espírito humano, mas podem ser deduzidos das experiências por 'abstração', ou seja, por um caminho lógico. $\mathrm{Na}$ verdade, foi apenas a teoria da relatividade geral que claramente reconheceu a inexatidão dessa concepçáo. Ela demonstrou que podíamos, com um fundamento bastante afastado do fundamento de Newton, explicar a respectiva área dos fatos experimentais de maneira até mais satisfatória e mais completa que o próprio fundamento de Newton permitiria" . E mais adiante: "Segundo nossa experiência, até hoje, temos o direito de estar convencidos de que a natureza é a realizaçáo do que podemos imaginar de mais simples matematicamente. Estou persuadido de que a construçáo puramente matemática nos permite encontrar esses conceitos e os princípios que os ligam entre si e que nos fornecem a chave da compreensão dos fenômenos naturais. Os conceitos matemáticos utilizáveis podem ser sugeridos pela experiência, mas não podem, em hipótese alguma, ser dela deduzidos". Eis as linhas gerais da grande conclusão de Einstein em física, eis suas preocupaçóes epistemológicas (Quadro XIII); o Quadro XIV recapitulará essa grande aventura epistemológica.

\section{Quadro XIV \\ AS GRANDES UNIFICAÇŌES EM FÍSICA}

\section{GALILEU:}

1602 simboliza a unificação Terra-Céu, introduz definitivamente a noçáo de Cosmo aberto antiaristotélico, as noçóes de inércia, a igualdade entre a massa de inércia e a massa de gravitaçáo. $O$ livro da natureza é escrito em linguagem matemática; suas leis são, portanto, universais.

\section{NEWTON:}

1687 descobre a equação de movimento dos corpos terrestres e a generaliza a todos os corpos no universo submetidos a uma força universal de açáo à distância, a força de gravi- 
tação. É estabelecida uma constante universal que caracteriza essas forças: $\mathscr{G}$.

\section{MAXWELL:}

1868-1870 unifica a óptica, a eletricidade e o magnetismo e introduz a noçáo de campo (com Faraday) e uma constante universal $\underline{c}$.

\section{J. J. THOMSON:}

1897 descobre o elétron e, portanto, a carga e.

\section{LORENTZ:}

1896 unificação da óptica com o eletromagnetismo e a química, com sua clássica teoria do elétron; absorção, difusão e refração da luz, propriedades ópticas dos metais, efeito Zeeman. Devemos a Lorentz a noção de renormalizaçáo de massa. A energia total do campo eletrostático de um elétron colocado na origem do laboratório é $U=\frac{1}{8 \pi} \int \vec{E}^{2} d^{3} x$ onde $\vec{E}=\frac{e}{r^{3}} \vec{r}$

é o campo de Coulomb válido no exterior de uma esfera de raio "a" tendo o elétron como centro e cuja carga está na superfície dessa esfera. $O$ cálculo dá

$$
U=\frac{e^{2}}{2} \int_{a}^{\infty} \frac{d r}{r^{2}}=\frac{e^{2}}{2 a}
$$

Segundo Lorentz, a massa do elétron seria dada pela energia de seu campo $\frac{U}{c^{2}}$; essa expressão é infinita para $a=0$, deve-se acrescentar-lhe um componente mecânico $\mathrm{m}_{0}$ :

$$
m=m_{0}+\frac{e^{2}}{2 c^{2} a}
$$

O ideal de Lorentz era atribuir a massa ao único campo e, portanto, estabelecer $m_{0}=0$ de onde o raio da esfera do elétron

$$
a \geq \frac{e^{2}}{2 m c^{2}}=r_{0}
$$

Introduziu-se, assim, uma constante $\mathbf{r}_{0}$ para dar uma idéia da dimensão linear do elétron.

\section{PLANCK:}

1900 descobre a quantificaçáo da energia e introduz a constante quantum de ação $\hbar$. 
EINSTEIN:

1905 a luz é, também, constituída de fótons com energia e impulsão, sendo

$$
E=\hbar w \vec{p}=n k \text {, w et } \vec{k}
$$

as variáveis freqüuência e número de ondas definidas pela onda associada ao fóton.

\section{EINSTEIN}

POINCARE

\section{LORENTZ:}

1905 descobrem a teoria da relatividade restrita, baseada em um grupo fundamental, o grupo de Lorentz inomogêneo ou grupo de Poincaré, que as equaçóes da física (em ausência de gravitaçäo) devem possuir.

\section{EINSTEIN:}

1905 estabelece o significado físico da relatividade, descobre a equivalência massa-energia $E=m c^{2}$.

\section{BOHR:}

1913 substitui o modelo clássico do átomo de Thomson-Lorentz por um modelo quântico que considera as contribuiçóes de Planck e Einstein nessa área; explica a origem do espectro dos elementos, afirma a existência de estados estacionários discretos dos átomos.

\section{EINSTEIN:}

1915 descobre a teoria relativística da gravitaçăo. Identifica a dinâmica gravitacional com a geometria do espaço físico. Introduz o projeto e o ideal da geometrizaçáo da física. Ápós os Pitagóricos de 2.000 anos atrás, após Platáo, Galileu e Newton, Einstein propóe a explicação do Universo em termos de geometria. E foi ele que, em 1917, fez nascer a cosmologia moderna.

\section{PAULI:}

1925 descoberta do princípio de exclusão.

\section{DE BROGLIE:}

1924 unificação das noçōes opostas corpúsculo-onda. Negando Parmênides e Aristóteles, segundo os quais um objeto não pode, ao mesmo tempo, ser e não ser, o corpúsculo está 
concentrado, mas sua probabilidade de presença pode estar por todos os pontos no espaço.

\section{SCHRODINGER}

\section{HEISENBERG}

\section{BORN}

\section{DIRAC:}

1925-1926 a construção da mecânica quântica, a teoria universal dos objetos e fenômenos atômicos que identifica os estados possíveis de um sistema físico com os vetores de um espaço de Hilbert. $\mathrm{O}$ conhecimento fundamental das coisas nấo pode ter as qualidades de certeza e de causalidade geométrica construídas por Einstein em sua teoria da relatividade e que queria ampliar a todas as teorias dos fenômenos físicos.

\section{PAULI}

\section{HEISENBERG}

DIRAC:

1927-1929 extensão da mecânica quântica à teoria dos campos. Descriçáo da produçáo e da aniquilação de partículas. Abandono da idéia de corpúsculos imutáveis. $O$ vazio é um sistema dinâmico onde existe flutuação de campos. Equação de Dirac.

\section{STRUCKELBERG}

\section{FEYNMAN}

\section{SCHWINGER}

TOMONAGA

\section{DYSON:}

1948 descoberta do método da renormalização capaz de eliminar dificuldades de divergência de certas teorias quânticas de campo, tal como eletrodinâmica.

\section{LEITE LOPES:}

1958 Propóe a igualdade e $=\mathrm{g}$ e a existência de bósons vetoriais neutros, a serem detectados na colisão elétron-nêutron.

\section{WEINBERG}

\section{SALAM}




\section{GLASHOW}

\section{THOOFT}

et alii:

1967 os elementos fundamentais da matéria, leptons e quarks, pertencem a um espaço de representaçăo de um grupo de calibre, os campos de força decorrem do postulado de invariância das equaçóes da matéria em relaçáo a esse grupo. Mas as massas e os campos físicos resultam de uma certa quebra de simetria, por meio de certos campos chamados de Higgs. A esperança é unificar, assim, as forças fraca, eletromagnética e forte no quadro dessas concepcóos. Falta, ainda, a unificaçáo com a gravitaçáo e novas perguntas e novos mistérios aparecem. O número e a natureza dos campos introduzidos são problemas abertos; assim como toda uma coleção de novas partículas, gluino, fotino, gravitino e outras que a supersimetria prediz. $O$ ideal de unificaçáo entre o campo de gravitaçáo e o campo eletromagnético, que Einstein perseguia durante os últimos trinta anos de sua vida e que náo conseguiu transformar em teoria, produziu, todavia, seus frutos sob a forma de uma ideologia herdada pelas geraçōes seguintes dos físicos. Esse ideal é a base das atuais teorias dos campos de calibre.

Náo menciono sua substancial obra na área política, também não me delongarei em discutir suas concepções sobre o caráter probabilístico do conhecimento que a mecânica quântica postula, cujos fundamentos esclareceu muito bem nas discussóes que manteve com Niels Bohr.

Viver na época de Einstein é um privilégio para todos nós. Particularmente, tive o privilégio, quando me dirigia da Universidade de Princeton ao Institute for Advanced Study para discutir com Pauli, com quem eu trabalhava em 1944 e 1945, de encontrar Einstein pelo caminho, que ele percorria toda tarde, entre o Instituto e sua casa em Mercer Street. A imagem de Einstein, simples e sorridente, parecia irradiar como um profeta saído das páginas de livros sagrados. Nós o v́ámos sempre no teatro Mc Cornick do campus de Princeton, nos concertos de Wanda Landowska, de Rudolf Serkin, de Adolphe Bush, do famoso quarteto de Budapeste. Einstein também ia às conferências no Instituto e na Universidade, entre as quais a de Bertrand Russell, sobre o confronto que inevitavelmente se produziria entre os Estados Unidos e a Uniáo Soviética após a Guerra. E, no Fine Hall, seu seminário sobre a última forma da teoria da unificaçáo atraiu grande audiência. Para mim foi um privilégio vê-lo e ouvi-lo, ao lado de Hermann Weyl, Von 
Neumann e Dirac. Foi um privilégio ter sido amigo, nessa época e alguns anos mais tarde, de Wolfgang Pauli e Robert Oppenheimer, de Oscar Klein e Hideki Yukawa, de Richard Feynmann, do matemático Salomon Lefschetz e do humanista Américo Castro, de Sandoval Vallarta, Marcos Moshinsky, de Abraham Pais e Jack Steinberger, de Josef Maria Jauch, de C. N. Yang e Ning Hu. Sua obra está certamente impregnada do que Aristóteles dizia sobre os Pitagóricos: "os elementos dos números são os elementos de todas as coisas e o céu inteiro é uma escala musical" . E o sutil Deus que Einstein invocava como o geômetra do Universo talvez fosse também o Deus das cantatas de Bach.

\title{
Resumo
}

O autor discute a evoluçăo da imagem física do mundo desde os filosofos gregos a Einstein e às idéias contemporâneas das teorias unificadas dos campos de calibre. A concepção atômica da matéria evolue da idéia de substância primordial de Tales aos leptons e quarks e aos quanta dos campos tais como gluons, bosons, vetoriais fracos e fortes.

A teoria quantica é a única capaz de explicar a identidade e a estabilidade da matéria, o mundo tal como o vemos.

\begin{abstract}
The author discusses the evolution of the physical description of the world form the greek philosophers to Einstein and the contemporany ideas on the unified gauge field theories. The atomic conception of matter evolves from the Thales idea of a primordial substance to leptons and quarks and the field quanta sech as gluons, weak vector basons and photons. The quantum theory is the only that can explain the identity and stability of matter, the world as we see it.
\end{abstract}

José Leite Lopes é físico exerceu cargo de secretário-adjunto da Secretaria de Ciência e Tecnologia do Rio de Janeiro. Foi professor-visitante da USP em $1984 \mathrm{e}$ um dos fundadores do Centro Brasileiro de Pesquisas em Física (CBPF). É Professor Emérito da Universidade de Strasbourg I.

Tradução de Belkiss Jasinevicius Rabello. $O$ original em francês encontra-se à disposição do leitor no IEA/USP para eventual consulta. 